\title{
Thermal energy enhances cell-mediated contraction of lax rat tail tendon fascicles following exercise
}

\author{
Michael Lavagnino \\ Kirollos Malek \\ Keri L. Gardner \\ Steven P. Arnoczky
}

Laboratory for Comparative Orthopaedic Research, Michigan State University, USA

Corresponding author:

Michael Lavagnino

Laboratory for Comparative Orthopaedic Research, Michigan State University

784 Wilson Road

East Lansing, 48824 Michigan, USA

E-mail: lavagnin@cvm.msu.edu

\section{Summary}

Background: the application of thermal energy (TE) has shown promise in the treatment of tendinopathy. However, the precise mechanism(s) of action of this therapy is unclear. The loss of tendon cell homeostatic tension, due to loadinginduced laxity, produces catabolic changes associated with tendinopathy. This catabolic activity can be inhibited through the re-establishment of a normal tensile environment via a cellular contraction mechanism. We hypothesized that application of TE will enhance the contraction rate of lax rat tail tendon fascicles (RTTfs) in an in vitro model.

Methods: following loading, 10 lax RTTfs from each mature rat $(n=5)$ were treated once daily for 7 days with TE by replacing the culture media at $37^{\circ} \mathrm{C}$ (control) with $42^{\circ} \mathrm{C}$ media. Using calibrated photographs, RTTf lengths were measured daily. Additional RTTfs were utilized to investigate any changes in material $(n=12)$ and/or histological $(n=12)$ properties with TE.

Results: TE significantly increased the contraction rate of RTTfs ( $p>0.001)$ without altering the material or histological properties.

Conclusion: these results demonstrate that TE significantly enhances the contraction rate of previously exercised tendons. The ability to more quickly re-establish a normal mechanobiological environment, thus minimizing any catabolic changes, may explain the beneficial effects reported with applied TE in tendinopathy treatment.
KEY WORDS: rat tail tendon, thermal energy, contraction, tendinopathy, laxity.

\section{Introduction}

Tendinopathy is a degenerative condition in tendons resulting from repetitive overuse ${ }^{1}$. While numerous therapeutic modalities have been directed at the symptoms associated with tendinopathy, none have specifically addressed potential alterations in the mechanical environment of tendon cells ${ }^{1,2}$. Recent studies have suggested that repetitive exercise can induce tendon laxity and alter the local mechanobiologic environment of tendon cells with the loss of cytoskeletal tensional homeostasis 2,3 . The loss of homeostatic tension in tendon cells has been shown to produce the catabolic changes associated with the pathology of tendinopathy ${ }^{2,4-6}$. Previous, studies have demonstrated the ability of tendon cells to contract lax tendons and re-establish normal homeostasis, thereby inhibiting the expression of catabolic mediators $^{3,7}$. However, this contraction has been shown to be inversely dependent on both age and degree of tendon laxity ${ }^{8}$. The ability of a therapeutic modality to enhance the cell-mediated contraction of a lax tendon would represent a significant step in restoring the normal mechanobiologic environment of tendon cells and the restoration of homeostasis.

The application of thermal energy (TE) by various modalities has shown promise in the treatment of tendinopathy ${ }^{1,9,10}$. The most widely used applications of thermal energy in the treatment of tendinopathy are hyperthermia and therapeutic ultrasound ${ }^{1,9}$. Thermal energy has been shown to accelerate the proliferation of cells ${ }^{10}$, aid in cytoskeleton remodeling ${ }^{11}$, increase local blood flow ${ }^{12}$, increase pain threshold ${ }^{13}$ and decrease tendon modulus ${ }^{14}$. In addition, thermal energy has been shown to increase cell migration ${ }^{15}$ and the cell-mediated contraction of collagen gels ${ }^{16}$. The potential of applied thermal energy to accelerate the ability of tendon cells to restore cytoskeletal tensional homeostasis in lax tendons may represent an additional mechanistic role of this modality in the treatment of tendinopathy.

Therefore, the purpose of the current study was to investigate the ability of thermal energy, applied in a clinically relevant manner with regard to temperature and exposure time, to enhance the rate of cell-mediated contraction of lax rat tail tendon fascicles in an in vitro test system. We hypothesize that the pulsed application of thermal energy will significantly in- 
crease the contraction rate of lax tendons following exercise over non-treated controls.

\section{Materials and methods}

Following Institutional Animal Care and Use approval and in accordance with the standards of the Muscle, Ligament, and Tendons Journal ${ }^{17}$, 10-18 rat tail tendon fascicles (RTTfs) were obtained immediately after euthanasia from each 4-month-old Sprague Dawley rat $(n=5)$. In all experiments, RTTfs were maintained in Dulbecco's Modified Eagle Medium with 10\% fetal bovine serum, $1 \%$ antibiotic/antimycotic, $0.2 \%$ gentamicin, and $0.75 \%$ ascorbate under tissue culture conditions $\left(37^{\circ} \mathrm{C}\right.$, $10 \% \mathrm{CO}_{2}$ ) over the duration of the experiment.

To induce laxity within the tendon, harvested RTTfs were placed taut into a custom-designed, low-load, tensile testing apparatus and then loaded to $2 \%$ cyclic strain at $0.17 \mathrm{~Hz}$ for 2 hours $^{8}$. Following the cyclic loading regime, the tendons were loaded until taut again to determine their elongated length. The percent elongation was calculated by dividing the change in length following loading by their initial length. After loading, the tendons were cut in half and divided into control and TE-treated groups.

To investigate the effect of a pulsed application of TE on tendon cells' ability to contract RTTfs, the RTTfs from the TE-treated group were pulsed with heat once daily for 7 days by replacing the $37^{\circ} \mathrm{C}$ media with media heated to $42^{\circ} \mathrm{C}$ in a water bath (Isotemp 220, Fisher Scientific, Waltham, MA, USA). Similarly, the control group's media was replaced once daily with $37^{\circ} \mathrm{C}$ media. This heating regime was based on previous clinical studies which demonstrated that daily application of thermal energy through pulsed ultrasound transiently increased local tissue temperatures by $5^{\circ} \mathrm{C}^{18}$. Precise changes in temperature induced by our in vitro heating regime were recorded at a frequency of $1 \mathrm{~Hz}$ using a thermister (Omega Engineering, Inc. Stamford, CT, USA) placed in one of the tissue culture wells while incubated at $37^{\circ} \mathrm{C}$. Prior to their treatment, tendons from both groups were photographed daily with an aligned ruler for calibration, and their lengths were measured using Image $\mathrm{J}$ software (U.S. National Institutes of Health, Bethesda, MD, USA, http://imagej.nih.gov/ij/).

To investigate any potential histological changes within the tissue, additional cyclically loaded RTTfs from each 7-day treatment group $(n=12)$ were fixed in $4 \%$ paraformaldehyde for histology. Paraffin sections were stained with hematoxylin and eosin, blinded to the individual analyzing the tendons, and photographed using an Infinity 1 microscopy camera (Lumenera Corporation, Ontario, Canada) on an Olympus BH-2 microscope (Olympus Corporation, Tokyo, Japan). To determine if any changes took place in the cellular density of the tissue, the photomicrographs of RTTf sections were analyzed using Image $\mathrm{J}$ software to count each cell nuclei completely in the photographed region of interest. The number of cell nuclei per area was calculated for each photomi- crograph using total number of cell nuclei in the area divided by the area of tissue measured.

To investigate any potential non-cellular alterations of the heat treatment on the material properties of the tendons, additional RTTfs $(n=12)$ were cyclically loaded as described above. To eliminate any cellular effect, these RTTfs underwent a freeze/thaw (x3) protocol in liquid nitrogen and sterile saline $\left(37^{\circ} \mathrm{C}\right)$ prior to being halved and starting the 7 days in culture with or without thermal treatment. Following the 7 days, RTTfs from each group $(n=12)$ underwent a stress-relaxation test to determine their viscoelastic material properties. Prior to testing, the cross-sectional area of each RTTf was determined from calibrated photomicrographs of each RTTf. The RTTfs were assumed to have circular crosssection and the area calculated from the mean of three diameter measurements taken perpendicular to the long axis of the fascicle using the Image $\mathrm{J}$ software. The RTTfs were gripped at each end in sawtooth clamps for a final gage length of approximately 17.8 $\mathrm{mm}$. The segments of RTTfs within the clamps were air-dried and placed between 2 pieces of emery board to eliminate slippage, and the test area of tendon between the grips was kept moistened with a room temperature phosphate buffered saline (PBS) solution. Each RTTf was mounted onto a custom-made material testing system in a PBS solution bath at room temperature. The testing system was equipped to measure load (5-lb load cell, Sensotec, Columbus, OH, USA) and grip-to-grip displacement (linear variable differential transformer, Lucas Schaevitz, Pennsauken, NJ, USA). Tendons were first loaded to $1 \mathrm{~g}$ to determine the initial RTTf length, and then displaced, using a motion controller (Newport, Fountain Valley, CA, USA), to 3\% strain at a constant rate of $0.41 \mathrm{~mm} / \mathrm{s}$ (approx $2.3 \%$ strain/s). The RTTfs were then maintained at this displacement for 10 minutes of stress-relaxation. Load and displacement values were recorded at $50 \mathrm{~Hz}$ with an analog-to-digital computer data acquisition system for the duration of the experiment. With the use of RTTf cross sectional area, load, and displacement values, the viscoelastic material properties of maximum modulus (maximum stress divided by applied strain) and equilibrium modulus (equilibrium stress divided by applied strain) were computed.

Statistical analysis of the change in RTTf length was performed using a 3 factor ANOVA (rat, day, and treatment) and an adjusted Bonferroni post-hoc with significance set at $P<0.05$. To test statistical changes in viscoelastic material properties and the number of cells per area with treatment, paired t-tests were utilized.

\section{Results}

The heating regime utilized in this study resulted in a transient increase in temperature levels of at least $2^{\circ} \mathrm{C}$ above the baseline $\left(37^{\circ} \mathrm{C}\right)$ for 4 minutes before returning to baseline by 13 minutes (Fig. 1).

Cyclic tensile loading of the RTTfs at $2 \%$ strain at $0.17 \mathrm{~Hz}$ for 2 hours resulted in a mean tendon elongation of $1.28 \pm 0.3 \%$ (Tab. 1 ). 
The pulsed application of thermal energy significantly enhanced the contraction rate of the lax RTTfs on days 5 ( $P=0.0132), 6(P<0.0001)$, and $7(P<0.0001)$ when compared to the paired control RTTfs (Figs. 2, 3, Tab. 1).

After seven days of treatment were no significant differences in either the maximum $(p=0.229)$ or equilibrium modulus $(p=0.274)$ between control $(171 \pm 59$ $\mathrm{MPa}, 130 \pm 53 \mathrm{MPa})$ and thermally treated $(206 \pm 90$ $\mathrm{MPa}, 155 \pm 57 \mathrm{MPa}$ ) rat tail tendon fascicles.

Histological assessment of both control and treated tendons revealed the presence of tendon cells on the surface of the tendons at 7 days which is to be expected. However, there was no significant difference $(p=0.188)$ in the density of cell nuclei between control $(691 \pm 157$ nuclei $\left./ \mathrm{mm}^{2}\right)$ and thermally treated $\left(613 \pm 155\right.$ nuclei $\left./ \mathrm{mm}^{2}\right)$ rat tail tendon fascicles after 7 days (Fig. 4).



Figure 1. Representative graph demonstrating the temperature change following the addition of media warmed to $42^{\circ} \mathrm{C}$.

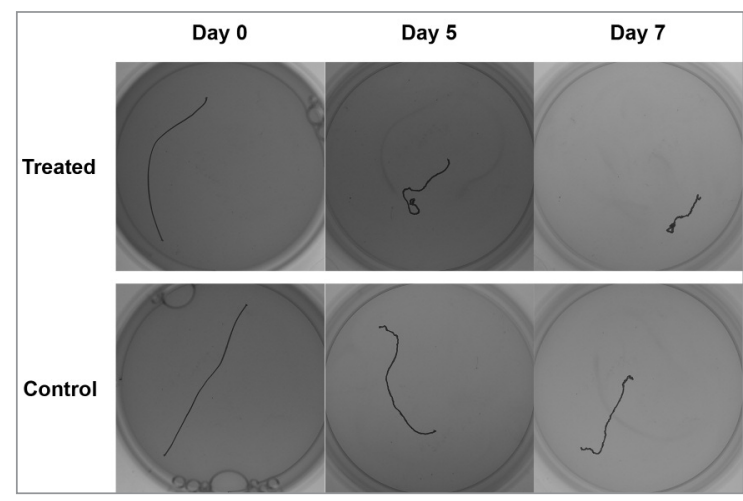

Figure 2. Representative images of treated and control tendons showing length changes at 0,5 , and 7 days.

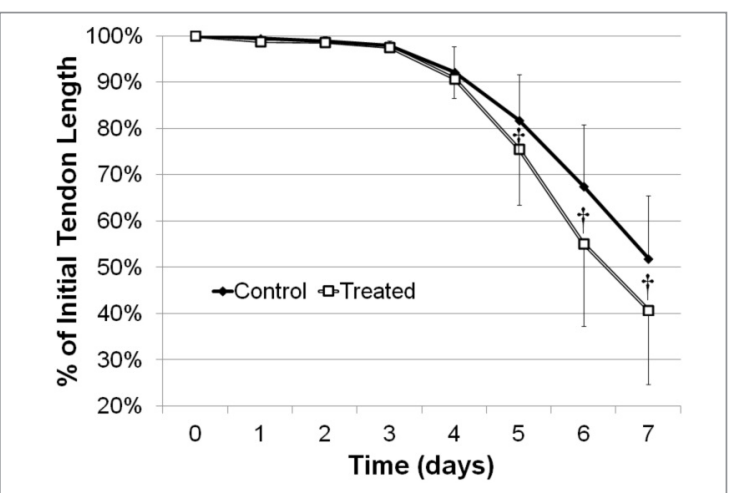

Figure 3. Graph showing the contraction rate of treated and control tendons over 7 days.

† Significant difference between treatments $(P<0.05)$.

Table 1. Percentage length of rat tail tendon fascicles (mean \pm SD) from each of 5 rats following cyclic load and subsequent cellular contraction over 7 days with $\left(42^{\circ} \mathrm{C}\right)$ and without $\left(37^{\circ} \mathrm{C}\right)$ applied thermal treatment.

\begin{tabular}{|c|c|c|c|c|c|c|c|c|c|c|}
\hline & \multicolumn{2}{|c|}{ Rat 1 ( $n=17)$} & \multicolumn{2}{|c|}{ Rat $2(n=18)$} & \multicolumn{2}{|c|}{ Rat $3(n=14)$} & \multicolumn{2}{|c|}{ Rat $4(n=12)$} & \multicolumn{2}{|c|}{ Rat $5(n=10)$} \\
\hline & $37^{\circ} \mathrm{C}$ & $42^{\circ} \mathrm{C}$ & $37^{\circ} \mathrm{C}$ & $42^{\circ} \mathrm{C}$ & $37^{\circ} \mathrm{C}$ & $42^{\circ} \mathrm{C}$ & $37^{\circ} \mathrm{C}$ & $42^{\circ} \mathrm{C}$ & $37^{\circ} \mathrm{C}$ & $42^{\circ} \mathrm{C}$ \\
\hline Initial & $\begin{array}{l}100.0 \\
\pm 0.0\end{array}$ & $\begin{array}{l}100.0 \\
\pm 0.0\end{array}$ & $\begin{array}{l}100.0 \\
\pm 0.0\end{array}$ & $\begin{array}{l}100.0 \\
\pm 0.0\end{array}$ & $\begin{array}{l}100.0 \\
\pm 0.0\end{array}$ & $\begin{array}{l}100.0 \\
\pm 0.0\end{array}$ & $\begin{array}{l}100.0 \\
\pm 0.0\end{array}$ & $\begin{array}{l}100.0 \\
\pm 0.0\end{array}$ & $\begin{array}{l}100.0 \\
\pm 0.0\end{array}$ & $\begin{array}{l}100.0 \\
\pm 0.0\end{array}$ \\
\hline $\begin{array}{l}0 \text { day } \\
\text { Postload }\end{array}$ & $\begin{array}{l}101.3 \\
\pm 0.0\end{array}$ & $\begin{array}{l}101.3 \\
\pm 0.0\end{array}$ & $\begin{array}{l}101.1 \\
\pm 0.0\end{array}$ & $\begin{array}{l}101.1 \\
\pm 0.0\end{array}$ & $\begin{array}{l}101.5 \\
\pm 0.0\end{array}$ & $\begin{array}{l}101.5 \\
\pm 0.0\end{array}$ & $\begin{array}{l}101.0 \\
\pm 0.0\end{array}$ & $\begin{array}{l}101.0 \\
\pm 0.0\end{array}$ & $\begin{array}{l}101.6 \\
\pm 0.0\end{array}$ & $\begin{array}{l}101.6 \\
\pm 0.0\end{array}$ \\
\hline 1 day & $\begin{array}{l}101.3 \\
\pm 2.0\end{array}$ & $\begin{array}{l}99.9 \\
\pm 2.3\end{array}$ & $\begin{array}{l}101.1 \\
\pm 2.2\end{array}$ & $\begin{array}{l}99.7 \\
\pm 2.5\end{array}$ & $\begin{array}{l}100.0 \\
\pm 1.8\end{array}$ & $\begin{array}{l}101.0 \\
\pm 3.1\end{array}$ & $\begin{array}{l}100.0 \\
\pm 1.4\end{array}$ & $\begin{array}{l}99.8 \\
\pm 1.1\end{array}$ & $\begin{array}{l}100.3 \\
\pm 1.9\end{array}$ & $\begin{array}{l}100.0 \\
\pm 1.2\end{array}$ \\
\hline 2 day & $\begin{array}{l}101.3 \\
\pm 2.8\end{array}$ & $\begin{array}{l}99.7 \\
\pm 1.9\end{array}$ & $\begin{array}{l}99.6 \\
\pm 2.7\end{array}$ & $\begin{array}{l}99.8 \\
\pm 2.7\end{array}$ & $\begin{array}{l}99.2 \\
\pm 2.5\end{array}$ & $\begin{array}{l}100.4 \\
\pm 3.5\end{array}$ & $\begin{array}{l}100.2 \\
\pm 1.6\end{array}$ & $\begin{array}{l}100.3 \\
\pm 1.7\end{array}$ & $\begin{array}{l}99.9 \\
\pm 1.9\end{array}$ & $\begin{array}{l}99.6 \\
\pm 2.2\end{array}$ \\
\hline 3 day & $\begin{array}{l}99.8 \\
\pm 2.3 \\
\end{array}$ & $\begin{array}{l}97.5 \\
\pm 2.2 \\
\end{array}$ & $\begin{array}{l}98.9 \\
\pm 1.8 \\
\end{array}$ & $\begin{array}{l}98.7 \\
\pm 3.5 \\
\end{array}$ & $\begin{array}{l}97.6 \\
\pm 3.4\end{array}$ & $\begin{array}{l}98.7 \\
\pm 4.4\end{array}$ & $\begin{array}{l}99.9 \\
\pm 1.8\end{array}$ & $\begin{array}{l}99.5 \\
\pm 1.6\end{array}$ & $\begin{array}{l}99.6 \\
\pm 3.9\end{array}$ & $\begin{array}{l}99.6 \\
\pm 4.9\end{array}$ \\
\hline 4 day & $\begin{array}{l}98.7 \\
\pm 2.1\end{array}$ & $\begin{array}{l}95.9 \\
\pm 3.0\end{array}$ & $\begin{array}{l}94.7 \\
\pm 3.6\end{array}$ & $\begin{array}{l}91.6 \\
\pm 6.6\end{array}$ & $\begin{array}{l}91.0 \\
\pm 9.1\end{array}$ & $\begin{array}{l}91.6 \\
\pm 6.8\end{array}$ & $\begin{array}{l}97.1 \\
\pm 2.0\end{array}$ & $\begin{array}{l}95.8 \\
\pm 2.5\end{array}$ & $\begin{array}{l}85.1 \\
\pm 13.9\end{array}$ & $\begin{array}{l}94.5 \\
\pm 8.2\end{array}$ \\
\hline 5 day & $\begin{array}{l}88.8 \\
\pm 8.2\end{array}$ & $\begin{array}{l}83.8 \\
\pm 10.3\end{array}$ & $\begin{array}{l}85.1 \\
\pm 8.5\end{array}$ & $\begin{array}{l}75.9 \\
\pm 17.4\end{array}$ & $\begin{array}{l}80.6 \\
\pm 14.7\end{array}$ & $\begin{array}{l}79.7 \\
\pm 11.0\end{array}$ & $\begin{array}{l}92.5 \\
\pm 5.4\end{array}$ & $\begin{array}{l}89.9 \\
\pm 5.1\end{array}$ & $\begin{array}{l}67.3 \\
\pm 20.6\end{array}$ & $\begin{array}{l}53.1 \\
\pm 19.9\end{array}$ \\
\hline 6 day & $\begin{array}{l}74.0 \\
\pm 14.9\end{array}$ & $\begin{array}{l}70.8 \\
\pm 17.8\end{array}$ & $\begin{array}{l}66.4 \\
\pm 15.7\end{array}$ & $\begin{array}{l}38.5 \\
\pm 19.2\end{array}$ & $\begin{array}{l}69.0 \\
\pm 20.6\end{array}$ & $\begin{array}{l}63.7 \\
\pm 15.0\end{array}$ & $\begin{array}{l}84.4 \\
\pm 13.9\end{array}$ & $\begin{array}{l}76.5 \\
\pm 11.7\end{array}$ & $\begin{array}{l}48.4 \\
\pm 21.7\end{array}$ & $\begin{array}{l}29.4 \\
\pm 16.5\end{array}$ \\
\hline 7 day & $\begin{array}{l}57.7 \\
\pm 20.0\end{array}$ & $\begin{array}{l}53.0 \\
\pm 25.4\end{array}$ & $\begin{array}{l}47.4 \\
\pm 16.3\end{array}$ & $\begin{array}{l}24.4 \\
\pm 9.0\end{array}$ & $\begin{array}{l}56.8 \\
\pm 21.8\end{array}$ & $\begin{array}{l}50.4 \\
\pm 16.8\end{array}$ & $\begin{array}{l}68.6 \\
\pm 19.2\end{array}$ & $\begin{array}{l}59.7 \\
\pm 14.5\end{array}$ & $\begin{array}{l}31.9 \\
\pm 13.7\end{array}$ & $\begin{array}{l}19.0 \\
\pm 8.1\end{array}$ \\
\hline
\end{tabular}




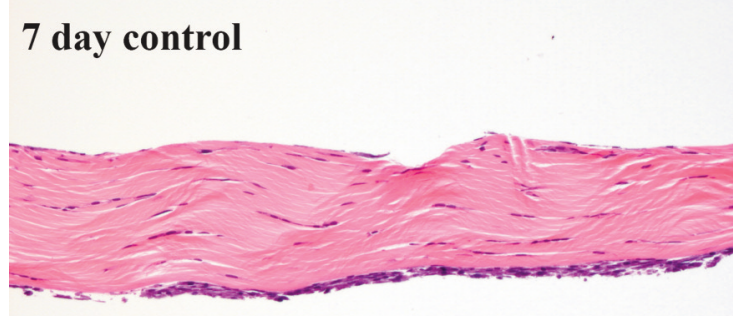

7 day thermal energy

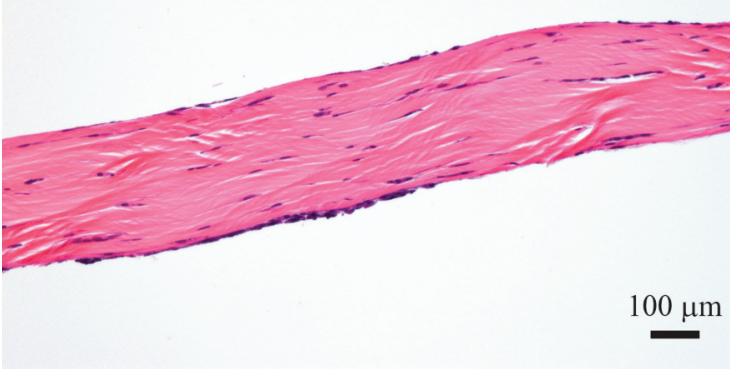

Figure 4. Representative photomicrographs of histological sections from control and thermal energy treated tendons at 7 days showing no difference in morphology or cellular density.

\section{Discussion}

The use of thermal energy, in the form of ultrasound or hyperthermia, has gained wide acceptance in the treatment of tendinopathy ${ }^{10,14}$. While the clinical benefit of applied thermal energy (i.e. therapeutic ultrasound, microwave diathermy) on tendinopathic tendons has been demonstrated ${ }^{1,9,10,19,20}$, the precise biological mechanism(s) by which thermal energy may exert a therapeutic effect in the treatment of tendinopathy are unclear ${ }^{10,21}$.

The results of the current study demonstrate that the pulsed application of thermal energy at clinical relevant levels over a 7 day period significantly enhances the cell-mediated contraction rate of previously exercised rat tendon fascicles. The daily application of thermal energy resulted in a $2^{\circ} \mathrm{C}$ temperature increase which was maintained for 4 minutes. This increase in local temperature is similar to previously recommended treatments $\left(1-4^{\circ} \mathrm{C}\right.$ over 3 to 9 minutes; 3-12 sessions) which have been shown to be efficacious in the treatment of tendinopathy ${ }^{9,18,19}$.

Previous studies have suggested that the beneficial therapeutic effects of TE on tendinopathy patients may be related to thermal energy-induced changes in the extracellular matrix and/or increases in cellular metabolism ${ }^{10,18,22}$. These include an increase in collagen extensibility ${ }^{23}$, an upregulation of proteins associated cytoskeletal organization [Rac1] ${ }^{22}$, as well as proteins associated with cell migration and tissue contraction [heat shock protein $27^{16,24}$, Rac125, alpha- smooth muscle actin ${ }^{15,26}$. Alterations in extracellular matrix properties and cellular density have both been shown to correlate with the rate of cell-based tendon contraction ${ }^{25}$. However, the current study did not demonstrate any statistically significant alterations in the viscoelastic material properties of the rat tail tendon fascicles following transient thermal treatments over 7 days. Similarly, the current study did not demonstrate any statistically significant alterations in the cellular density in the rat tail tendon fascicles following the prescribed transient thermal treatments over 7 days. This suggests that cell proliferation was not a factor in the cell-based tendon contraction seen in this study. Alterations in cellular metabolism due to the thermal treatments may also be an important contributor to tissue contraction. Heat shock protein 27 (HSP27) has been shown to regulate fibroblast adhesion, elongation, and migration along with the contraction of extracellular matrix ${ }^{16,24}$. Rac1 (a small GTPase) is another important cellular protein involved in cytoskeletal organization ${ }^{22}$ and plays a critical role in extracellular matrix contraction ${ }^{25}$. Both of these proteins have been shown to be increased by short term exposure to increased temperature $\left(41^{\circ} \mathrm{C}\right)^{16,22}$. Alpha smooth-muscle actin synthesis has also been shown to be an important factor in the cell-mediated contraction of lax tendons ${ }^{3}$ and has been shown to increase in fibroblasts following exposure to ultrasound irradiation $^{26}$. Although these proteins have been shown to be critical to matrix contraction ${ }^{3,16,24,26}$ and are altered with transient increased temperature ${ }^{16,22,26}$ their precise role or that of other proteins in enhancing tendon contraction is unclear and requires further study. A rat tail tendon fascicle system employed in the current study has been previously used to study the effect of age and exercise ${ }^{8}$ on the cell mediated recovery of cytoskeletal tensional homeostasis in lax tendons $^{3,7}$. While this tissue system cannot precisely duplicate the varied and complex pathology that can be present in clinical cases of tendinopathy, numerous studies from our lab have demonstrated that many of the key pathologic features of tendinopathy are elicited following loss of cytoskeletal tensional homeostasis $2,4-6$. The longer the duration of this loss of tensional homeostasis the more profound are the pathological changes ${ }^{5}$. Therefore, the ability of applied thermal energy to significantly accelerate the contraction mechanism of exercised tendons demonstrated in the current study may limit the extent of these pathological changes and offer another potential mechanism by which the application of thermal energy has shown to be beneficial in some cases of tendinopathy $10,18,20,21,26$.

An obvious limitation of the current study is the method by which the thermal treatment was applied. While the addition of heated media to the rat tail tendon fascicles certainly does not take into account any potential non-thermal effects associated with the application of ultrasound ${ }^{21}$ it does reflect both the number of treatments and the short duration of the local temperature increases achieved in pulsed ultrasound applications that have shown to be efficacious ${ }^{9,18,19}$. 
Other therapeutic modes of thermal energy which have demonstrated positive results in the treatment of tendinopathy such as microwave diathermy, maintain temperature increases similar to that utilized in the current study, albeit for longer times (30 minutes) ${ }^{14}$. However, the heat dissipating effect of local blood flow over this longer heating period is difficult to estimate ${ }^{21}$ and impossible to replicate in an in vitro system. The ability to consistently deliver a clinically relevant temperature increase over a specified period of time and confirm our hypothesis is a strength of the in vitro system.

The results of the current study demonstrate a significant increase in the rate of tendon cell contracture following in vitro application of thermal energy in a clinically relevant dose/duration treatment regime. These findings suggest another potential mechanistic rationale for the use of thermal energy in the treatment of tendinopathy. However, additional studies are needed to clarify the precise role(s) of thermal energy in addressing the various pathological manifestations associated with tendinopathy.

\section{Declaration of interest statement}

The authors report no conflicts of interest.

\section{References}

1. Andres BM, Murrell GA. Treatment of tendinopathy: what works, what does not, and what is on the horizon. Clin Orthop Relat Res. 2008;466(7):1539-1554.

2. Arnoczky SP, Lavagnino M, Egerbacher M. The mechanobiological aetiopathogenesis of tendinopathy: is it the over-stimulation or the under-stimulation of tendon cells? Int J Exp Pathol. 2007;88(4):217-226.

3. Gardner K, Lavagnino M, Egerbacher M, Arnoczky SP. Re-establishment of cytoskeletal tensional homeostasis in lax tendons occurs through an actin-mediated cellular contraction of the extracellular matrix. J Orthop Res. 2012;30(11):16951701.

4. Egerbacher M, Arnoczky SP, Caballero O, Lavagnino M, Gardner KL. Loss of homeostatic tension induces apoptosis in tendon cells: an in vitro study. Clin Orthop Relat Res. 2008;466(7):1562-1568.

5. Hannafin JA, Arnoczky SP, Hoonjan A, Torzilli PA. Effect of stress deprivation and cyclic tensile loading on the material and morphologic properties of canine flexor digitorum profundus tendon: an in vitro study. J Orthop Res. 1995;13(6):907914.

6. Arnoczky SP, Tian T, Lavagnino M, Gardner K. Ex vivo static tensile loading inhibits MMP-1 expression in rat tail tendon cells through a cytoskeletally based mechanotransduction mechanism. J Orthop Res. 2004:22(2):328-333.

7. Arnoczky SP, Lavagnino M, Egerbacher M, Caballero O, Gardner K. Matrix metalloproteinase inhibitors prevent a decrease in the mechanical properties of stress-deprived tendons: an in vitro experimental study. Am J Sports Med. 2007; 35(5):763-769.
8. Lavagnino M, Bedi A, Walsh CP, Sibilsky Enselman ER, Sheibani-Rad S, Arnoczky SP. Tendon Contraction After Cyclic Elongation Is an Age-Dependent Phenomenon: In Vitro and In Vivo Comparisons. Am J Sports Med. 2014;42(6):14711477.

9. Giombini A, Di Cesare A, Safran MR, Ciatti R, Maffulli N. Shortterm effectiveness of hyperthermia for supraspinatus tendinopathy in athletes: a short-term randomized controlled study. Am J Sports Med. 2006;34(8):1247-1253.

10. Tsai WC, Tang ST, Liang FC. Effect of therapeutic ultrasound on tendons. Am J Phys Med Rehabil. 2011;90(12):1068-1073.

11. Sunyer R, Ritort F, Farré R, Navajas D. Thermal activation and ATP dependence of the cytoskeleton remodeling dynamics. Phys Rev E Stat Nonlin Soft Matter Phys. 2009;79(5 Pt 1):051920.

12. Milnor WR. Autonomic and peripheral control mechanisms. In: Mountcatel VB, ed. Medical Physiology. Vol. 2. 14th ed. St. Louis, MO: CV Mosby; 1980:1047-1060.

13. Downing DS, Weinstein A. Ultrasound therapy of subacromial bursitis. A double blind trial. Phys Ther. 1986;66(2):194-199.

14. Giombini A, Giovannini V, Di Cesare A, et al. Hyperthermia induced by microwave diathermy in the management of muscle and tendon injuries. Br Med Bull. 2007;83:379-396.

15. Tsai WC, Chen JY, Pang JH, Hsu CC, Lin MS, Chieh LW. Therapeutic ultrasound stimulation of tendon cell migration. Connect Tissue Res. 2008:49(5):367-373.

16. Mayes AE, Holyoak CD. Repeat mild heat shock increases dermal fibroblast activity and collagen production. Rejuvenation Res. 2008;11(2):461-465.

17. Padulo J, Oliva F, Frizziero A, Maffulli N. Muscles, Ligaments and Tendons Journal. Basic principles and recommendations in clinical and field science research. MLTJ. 2014;4:250-252.

18. Chan AK, Myrer JW, Measom GJ, Draper DO. Temperature changes in human patellar tendon in response to therapeutic ultrasound. J Athl Train. 1998;33(2):130-135.

19. Chester R, Costa ML, Shepstone L, Cooper A, Donell ST. Eccentric calf muscle training compared with therapeutic ultrasound for chronic Achilles tendon pain-a pilot study. Man Ther. 2008;13(6):484-491.

20. Oliva F, Via AG, Rossi S. Short-term effectiveness of bi-phase oscillatory waves versus hyperthermia for isolated long head biceps tendinopathy. Muscles Ligaments Tendons J. 2012;1(3):112-117.

21. Baker KG, Robertson VJ, Duck FA. A review of therapeutic ultrasound: biophysical effects. Phys Ther. 2001;81(7):13511358.

22. Han SI, Oh SY, Woo SH, Kim KH, Kim JH, Kim HD, Kang HS. Implication of a small GTPase Rac1 in the activation of c-Jun $\mathrm{N}$-terminal kinase and heat shock factor in response to heat shock. J Biol Chem. 2001;276(3):1889-1895.

23. Lehmann JF, de Lateur BJ. Therapeutic heat. In: Lehmann JF, ed. Therapeutic Heat and Cold. Baltimore, Md: Williams \& Wilkins; 1990: 417-581.

24. Hirano S, Shelden EA, Gilmont RR. HSP27 regulates fibroblast adhesion, motility, and matrix contraction. Cell Stress Chaperones. 2004;9(1):29-37.

25. Tovell VE, Chau CY, Khaw PT, Bailly M. Rac1 inhibition prevents tissue contraction and MMP mediated matrix remodeling in the conjunctiva. Invest Ophthalmol Vis Sci. 2012;53(8):4682-4691.

26. Maeshige N, Terashi H, Aoyama M, Torii K, Sugimoto M, Usa$\mathrm{mi}$ M. Effect of ultrasound irradiation on a-SMA and TGF- $\beta 1$ expression in human dermal fibroblasts. Kobe J Med Sci. 2011;56(6):E242-E252. 